\title{
Memórias e práticas no ensino e Pesquisa de História
}

Helenice CIAMPI

RESUMO

() texto visa socializar os resultados e problemas enfrentados no projeto Saber Escolar: memórias e práticas de professores de Historia da rede municipal da cidade de São Paulo que coordeno desde 2005 na PUC/SP. Explicitarei a problemática, objetivos e metodologia centrando-me na pesquisa realizada em 2007, na subprefeitura de Vila Nova Cachoeirinha e Casa Verde 2 .

Palavras-chaves: Ensino de História - Saber escolar - Saber docente.

A formação de professores apresenta-se como espaço privilegiado e promissor para o questionamento de tradições de ensino arraigadas e para o desenho de soluções criativas no cotidiano escolar. Nesse sentido, emerge a intenção de registrar as memórias, práticas e saberes de professores para, conjuntamente, repensar a formação do profissional de História. Privilegiarei recortes da memória social dos docentes entrevistados, pois o senso de historicidade é formado com referências que extrapolam a universidade e o conhecimento sistematizado. Implica em um campo social que põe em destaque a força de outros processos, lugares e agentes sociais. A memória, "porta a marca da experiência, por maiores mediações que ela tenha sofrido. Têm estampadas, as paixões dominantes em seu tempo." (SAMUEL, 1997).

\section{A pesquisa}

Meu objeto de estudo são as memórias e práticas de professores de História,

' Professora Titular e Pesquisadora, integrante do Grupo de Pesquisa da Faculdade de Educação da PUCSP: Formação docente e cotidiano escolar, credenciado pela CNPq.

- liste texto foi parcialmente apresentado na Mesa-Redonda 3 Memória Ensino de Historia no VIII Encontro Nacional de Pesquisadores do Ensino de Historia (ENPE) realizado na Faculdade de Educação da USP, em fevereiro de 2008 . 
buscando centrar a reflexão sobre o processo de constituição dos saberes docentes e sua relação com o saber escolar, enquanto um saber de configuração cognitiva própria e original da cultura escolar. (CHERVEL, 1999) Partindo do pressuposto que a escola é uma construção histórica, e que a "ênfase nos usos diferenciados de objetos ou modelos culturais desloca o olhar do historiador da educação dos modelos pedagógicos (tenham eles o caráter de leis, regulamentos, preceitos, doutrinas ou sistemas pedagógicos) para as práticas diferenciadas de apropriação deles", questionar o que os professores de História "fazem com os modelos que lhes são impostos ou com os objetos que the são distribuídos". (WARDE, e CARVALHO, 2000.) Muitas vezes o profissional segue "modelos" de práticas do professor que o marcou. Outras vezes sua prática é marcada pelas experiências de vida pessoal e profissional. Por vezes segue à risca as determinações legais, ora se opõe contra as mesmas.

Maurice Tardif afirma que os saberes da experiência dos professores adquiridos ao longo de sua prática docente são articuladores centrais dos saberes curriculares, da formação pedagógica e disciplinar específica, pois funcionam como uma espécie de filtro por onde as imposições normativas são acatadas, modificadas ou ainda quebradas. Mas não esclarece se os saberes da experiência são o resultado de um acúmulo temporal de sucessos e reveses profissionais que permitem ao docente lidar com o modelo escolar, do savoir-faire mais imediato adquirido no vis-à-vis do contexto escolar ou das competências profissionais construídas pela releitura da experiência por meio da memória de suas práticas. Para Philippe Perrenoud

(...) a competência, ao mesmo tempo em que mobiliza a lembrança das experiências passadas, livra-se delas para sair da repetição, para inventar soluções parcialmente originais, que respondem, na medida do possível, à singularidade da situação presente. (1999)

Portanto, uma questão que considero de fundamental importância, ésaber como os professores, têm enfrentado permanências e mudanças no seu cotidiano a partir da releitura de suas experiências passadas, obviamente mediadas por suas memórias, e como tais rememorações são ativadas em seus saberes e práticas docentes no presente.

0 grande desafio é articular a discussão do saber escolar com a memória no momento da análise. Como as experiências pretéritas auxiliam na mobilização dos saberes docentes no presente? Qual o papel da memória na trajetória e for- 
mação de um professor de historia? Tentar perceber como os professores em suas práticas enfrentaram e enfrentam os conflitos entre as suas experiências vividas e as imposições e urgências do presente na formação dos seus saberes.

Nossa hipótese de trabalho é que os dados coletados sobre os profissionais pesquisados podem oferecer "vestígios" sobre as marcas deixadas pela formação acadêmica e suas articulações com a cultura escolar, experiências de vida pessoal e práticas cotidianas. Enfim, é procurar entender porque estes profissionais ensinam o que ensinam. Como redimensionam os conhecimentos e a cultura escolar? Como justificam a sua prática?

Outra hipótese de trabalho é tentar articular a constituição dos saberes docentes, numa perspectiva histórica, agrupando os profissionais pesquisados por décadas, períodos nos quais estes professores tiveram sua formação acadêmica. Tais agrupamentos por "gerações" abarcariam os docentes formados nas décadas de 70, 80 e 90, identificados com os professores em exercício, com a faixa etária entre 50, 40 ou 30 anos, respectivamente. Analisar como aparecem as diferenças e os conflitos entre suas práticas e saberes.

Gostaria de deixar claro que, na articulação das memórias e práticas de professores de História, não estou negando os limites de atuação destes profissionais e nem tampouco uma prática que, muitas vezes, cai nas armadilhas do cotidiano e aparentemente restringe-se à memorização, à aquisição de conhecimentos e/ ou compreensão de dados. Há algo mais que articula a mobilização das "competências docentes", configurando-as de uma forma específica em cada prática. É o substrato cultural que delineia a configuração do saber docente que procuro identificar, por entre os véus de suas memórias, os vestígios de suas práticas.

o projeto tem como objetivos registrar memórias e práticas de professores de História da rede pública municipal da cidade de São Paulo, das séries finais do Ensino Fundamental tendo, como pesquisadores, alunos da graduação, licenciatura em História da PUCSP; propiciar via estágio supervisionado, e elaboração do TCC, um espaço para o exercício da pesquisa, troca de experiências e diálogo entre o aluno universitário e o profissional de História da rede municipal de ensino.

Dois são os instrumentos de pesquisa: Entrevistas e observação de aulas com os professores de História das escolas selecionadas 3 . As entrevistas serão realizadas segundo a metodologia de trabalho em História Oral.

Entre os motivos para entrevistar professores das séries finais do ensino fundamental, destaco: o contingente maior de escolas e docentes e o início do trabalho com profissionais "especialistas". Suas práticas e saberes certamente deixam marcas na formação dos alunos. 
A história oral é um método interdisciplinar, um caminho cruzado por vários pesquisadores, sejam historiadores, sociólogos, antropólogos, literatos ou outros. (THOMPSON, 2002, p.6; MEIHY, 2005). A memória individual interessa na medida em que permite o conhecimento do fenômeno social. Mais do que a soma das memórias individuais, "a memória coletiva é um fenômeno construído pela força de fatores externos que circunstanciam um determinado grupo, marcando sua identidade". É esta identidade que dá consistência, à memória de um grupo, e "é a memória que distingue sua identidade. Uma não existe sem a outra". (MEIHY, 2005, p.65)

0 projeto segue a História Oral Temática. Este gênero articula o uso da documentação oral ao das fontes escritas, no caso o registro de observação das aulas. 0 fato de iniciar a entrevista com questões que remetem a história de vida é provocar uma "viagem no tempo", recurso que muitas vezes desmobiliza discursos prontos e laudatórios.

Jacy Seixas, (2002) busca refletir sobre o movimento e os tempos da memória, "sobre o caráter de descontinuidade que a singulariza e sobre a função aí inscrita de atualização das experiências outrora vividas".Quer a autora nos mostrar que a memória "não é estática, nem seu volume e conteúdos são fixos; ela se movimenta, e esse movimento configura uma espiral no espaço e no tempo, que se inicia e se atualiza no presente e, de forma espontânea, e se prolonga em diferentes épocas".

A memória não é uma mera retrospectiva, um resgate passivo e seletivo de momentos do passado que vem "compor" o presente. "A memória não é regressiva (algo que parte do presente fixando-se no passado); ela é prospectiva e, mais do que isso é projetiva, lançando-se em direção ao futuro". A memória é uma espiral em (ex) tensão, que configura em seu movimento planos diferenciados a serem percorridos pelos sujeitos. Isto significa entender a tensão existente nos campos ou espaços da memória, isto é, como toda lembrança se transforma à medida que se atualiza e, an fazê-lo enriquece e desenvolve a percepção atual, que por sua vez atrai outras lembranças complementares.

A memória não é impessoal. Depende do sujeito e do momento em que será "solicitada". A lembrança que se atualiza não o faz de forma uniforme, "nem sua extensão está dada. A memória não se possui, mas se percorre. A memória supõe um espaço elástico no qual se move interessadamente, supõe 
uma seqüência de planos de 'profundidade' que colocam em pauta a noção do tempo" (SEIXAS, 2002, p.46).

\section{Identificação dos Sujeitos}

Em $2007^{4}$ foram observados dez professores e somente nove conceberam entrevistas: quatro homens e cinco mulheres de seis escolas municipais. São sete professores trabalhando com crianças e dois com jovens e adultos.

Todos os docentes são efetivos. Com exceção de um, todos tem licenciatura plena. Cinco são formados pela PUCSP, quatro fizeram bacharelado em Historia e um em Ciências Sociais. Dois fizeram licenciatura na Faculdade Integrada do Ipiranga, um licenciou-se pela Faculdade Teresa Martin e outro em Guarulhos. Um é formado em Filosofia, fez seminário. Além destas graduações os docentes antes de optarem pela História, fizeram cursos técnicos: secretariado, engenharia de produção (Fatec), contabilidade, e administração de empresas.

Destes, cinco professores vieram do interior do Estado de S.P., um do Mato Grosso do Sul, e dois têm origem estrangeira: pais japoneses, mas casaram-se no Brasil; outro tem pai espanhol e a mãe portuguesa que vieram em busca do sonho americano. Todos de origem muito simples, predominando a área rural, (4) pais que trabalhavam na terra. Vindo para a cidade de S.P. foram gari, entregador de marmita em uma pensão, sapateiro e taxistas (2). Suas mães foram trabalhar como domésticas (2) e costureiras (2). Os demais pais foram bancários (2), radialista (1) e militar (1). As maiorias destes pais cursaram até a $4^{a}$ série primária, sendo duas mães analfabetas.

Infância pobre, porém com boas lembranças da casa de taipa, chão de terra, fogão a lenha, quintal, rio. Brincadeiras que inventavam, pois não tinham dinheiro para tal. Jogar amarelinha, bola de gude, subir nas árvores, balançar nas árvores, "rolar na grama, rolar na lama". Infância saudável, família presente,

\footnotetext{
* Esse processo de traballho tem possibilitado, aos estagiários, uma troca de experiências interativas de fundamental importância para a sua prática pedagógica, assim como tem permitido apropriaren-se da metodologia da Historia () ral como ferramenta de produção de conhecimento. Os estagiários do projeto em 2007 foram: Atair ('ama Silva, Aparecida Cardoso, Danilo Ferreira da Fonseca, Emílio Cordeiro, Fabio Caetano da Rocha, Juliána Vacáro,Marta Alves da Silva, Patrícia Fortunato Dias, Paola Garcia e Roberto Canado Júnior.

As escolal olservadas foram: EMEF Angelina Maffei Vita, EMEF Clóvis Graciano, EMEF Comandante Garcia D'Ávila, EMIEF Marcílio Dias, EMEF Marcos Melega e EMEF Tenente Aviador Frederico Gustavo dos Santos.
} 
com exceção do docente que veio do Mato Grosso após a separação dos pais. Todos freqüentaram a escola pública e mencionam a formação precária e dificuldades ao fazer a Universidade, especialmente a PUC/SP.

Foram todos "estudantes trabalhadores" sendo o seu primeiro emprego como Office boy, (2) secretárias (2), empregado numa empresa de tratamento de água e esgoto, estagiária na secretaria das finanças, e um pequeno comércio que não deu certo. Com exceção do docente mais jovem, e de duas professoras na faixa dos quarenta, nas memórias dos seis outros depoentes, perpassa um clima político dos anos de 1980 que moldou sua formação e vida profissional.

Os nove docentes são de gerações diferenciadas: três entre 50/60 anos, cinco na faixa de 40/50 anos e $u m$ com idade entre 30/40 anos. Respectivamente, tem vinte e cinco e trinta e quatro anos de magistério, a maioria entre catorze a vinte anos de magistério e um docente com nove anos de docência.

Neste texto, por motivo de espaço centrar-me-ei nos três docentes da geração dos anos de 1970 para possibilitar uma analise mais detalhada da mobilização dos saberes destes profissionais.

\section{Geração da década de 1970}

São três os professores entre 50/60 anos. A descendente de japoneses, 0 ex-seminarista e o professor-diretor. A descendente de japoneses lembra que o pai, radiador de bela voz contava histórias toda quarta-feira à noite, para os irmãos e a criançada da rua, inclusive com sonoplastia. E, quando faltava luz, histórias de terror. Sabia a "Barsa" de cor. A mãe costureira contribuía confeccionando fantasias para a realização de peças teatrais. Morava em Andradina, próximo da Igreja matriz, que a marcou profundamente, pois era o espaço social da época. Corria atrás do "porquinho da Índia" e colhia borboletas para fazer aqueles quadros de insetos. Participou do Instituto de Amigos de Jesus e ia às fazendas da região ensinar as pessoas a lerem, um marco em sua vida. Participou do primeiro movimento dos Sem Terras, sendo presa aos 17 anos. Fez normal e iniciou a carreira como professora primária. 0 fato de fazer História "tem alguma coisa a ver com a minha raiz lá do MST, alguma coisa que ficou inconsciente".

Embora justifique sua atuação profissional pelo contato com movimentos sociais, o que certamente a influenciou na construção de uma visão mais crítica 
e coletiva do processo histórico, é notório o papel dos pais como "narradores do cotidiano". O pai, radialista da pequena cidade, utilizava a voz como instrumento de trabalho e dividia, nas horas de lazer, seu repertório profissional para contar histórias para a garotada da rua e, muito provavelmente, as tornava tão vivas pelo recurso da sonoplastia, que tanto impressionou a menina, como ficou "gravado" na lembrança da mulher que se tornou. Além disso, ele também sabia muitas coisas "de cor" e, verdade ou não, a metáfora do narrador enciclopédico funcionava aqui como um "arrimo da memória" para marcar na lembrança o papel do "contar histórias" em sua vida. A mãe, por sua vez, costurava, tecia fantasias para outras histórias realizadas no teatro da cidade, o que não deixa de ser outra forma de registrar o papel da narrativa como professora de história. No espaço de atuação de seus pais narradores e da sua vida de menina, a cidade pequena e a Igreja central eram forças gregárias que potencializavam a importância das sociabilidades cotidianas tecidas pelos fios da narratividade e atualizadas nas memórias da depoente.

Outro docente, na faixa dos cinqüenta anos, lembra que "no interior tudo girava em torno da Igreja: a praça da matriz, a vida social, o ponto de encontro nas missas dominicais. Estudo era para os ricos. Um luxo", não sendo um valor para os seus pais e sim o trabalho na roça. Foi coroinha, importante naquela época, sobretudo em cidades do interior e fez seminário. Como tinha filosofia, acabou dando aulas de $1^{\text {a a }} 4^{\text {a }}$ " "todos juntos numa única sala". o fato de ter feito seminário o ajudou a ter boa comunicação com o público, boa oratória. Em São Paulo, fez complementação em História, pois gostava de História e queria completar a carga horária. Mais uma vez, a praça da matriz surge como um "lugar da memória" que agrega a um só tempo o espaço da criança no passado, a profissão docente no presente e o papel da narrativa que alinhava o circuito de sociabilidade entre a cidade gregária, a profissionalidade em construção e a infância já terminada.

o terceiro professor, o mais velho entre os depoentes, estudou no Instituto de Educação de Penápolis, excelente colégio na avaliação do docente. Todos na sua família fizeram curso superior. Foi coordenador da Pastoral da Juventude em Santana e participou do movimento do custo de vida na Praça da Sé. Quando lá chegou sofreu "bomba de gás lacrimogêneo, porrada para tudo que é canto". Isto o colocou para pensar.

Cioso da obediência, temor aos pais nunca os afrontava. Só o fez, intelectu- 
almente, quando deixou as exatas e foi fazer ciências sociais. Sentia-se alienado e correu atrás de formação política. Desde então começou a escrever poemas e cartas para a namorada, a mãe de sua filha, que participava ativamente da luta política no PT. Separou-se, pois a paixão política a levava para outras instâncias.

0 professor fez vários concursos: dois para a Academia Militar de Agulhas Negras, não passou, mas foi aprovado na Força Aérea de Pirassununga. Entretanto, foi rejeitado "por hemo-afetividade: muito preso à família não adequado para a carreira militar". Depois de ser professor de sociologia e história por vinte anos hoje é diretor da escola em que lecionava.

Para esse professor, a cidade já não inspira o caráter aglutinador de experiências na sua memória e a família ganha centralidade justamente por se opor a ela, é uma "imagem em negativo" se comparado aos dos depoimentos anteriores. A cidade de São Paulo é o espaço da dispersão e o da família da repressão, a luta em movimentos sociais indica a busca também por um espaço mais coletivo e democrático da cidade e por se libertar da "hemo-afetividade" familiar e autoritária dentro de si mesmo. 0 espaço da memória é guiado por uma tentativa de coletivizar a cidade que se dispersa e de se individualizar da família centralizadora. Dirigir a sua própria vida e a dos outros se expressa bem na atividade que exerce hoje como diretor de escola.

A tônica nas experiências passadas desta geração nascida na década de 1940/50 é a cidade e a família no passado, portanto, o espaço público e privado, se interpenetrando como um lócus da profissionalidade docente no presente, muito embora tais fatores não apareçam nos depoimentos como determinantes para sua carreira no magistério atualmente, o que, de certa forma, indica o esquecimento operado pela memória.

O sentido lembrado e, portanto, freqüente em suas falas, é a relação entre movimentos sociais e com forte influência da Igreja Católica. Na dialética da lembrança e do esquecimento, próprio do trabalho de quem memoriza, a cidade e a família vêm apenas a emoldurar uma escolha "mais séria" ancorada nos movimentos sociais o que, muito provavelmente, deve ter sido reforçado pela necessidade de dar um depoimento "mais coerente" a um pesquisador da área de história sobre o seu compromisso político com a docência hoje. Há um jogo entre a cidade/família "esquecidas" e movimentos sociais/Igreja Católica "lembrados" na construção de um sentido para sua experiência docente em sala de aula. Resta 
saber como tais experiências articulam-se na mobilização de seus saberes em seus espaços de trabalho?

A docente descendente de japoneses relembra a forte influencia do pai no período da infância e da juventude. Ser professor de historia significa formar o cidadão, mas como fazê-lo hoje se a educação que deveria ser feita pela família não ocorre? "Semana passada a gente os levou [os alunos] na estação de tratamento de água da Sabesp. Alguns pais vieram me perguntar por que a gente tava levando as crianças na estação de tratamento de água. Aí eu falei: ué pra eles terem conhecimento, nem todo mundo pode ir nesses lugares, as visitas são restritas".

Insiste na desestruturação das instituições familiar e escolar numa sociedade tão desigual. Apesar dos impasses resiste e o faz com suas experiências passadas: a alfabetização. Esta tentando alfabetizar alunos de $5^{\text {a }}$ serie. "Alfabetizar mesmo, voltando lá no meu tempo que era professora de $1^{\mathrm{a}}$ a $4^{\mathrm{a}}$ série, trabalhando com letrinhas móveis. (...) São doze alunos que estou trabalhando. Toda segunda feira à tarde eu tiro eles da sala que estão para alfabetizar". Apresenta como possíveis razões desta situação vários fatores: a mudanças da sociedade que a escola não acompanhou, pela política educacional deficiente, pela implantação equivocada dos ciclos, pela questão da inclusão que só exclui.

"Na 6asérie temos seis alunos de inclusão, quer dizer não sabem ler e tem problemas neurológicos. Deveriam ser encaminhados para um curso profissionalizante, não sei, alguma coisa tem que ser feita porque eles lá não vão aprender mesmo". E completa: "a formação de professores hoje esta baseada muito mais em teorias do que em práticas. Os professores novos sabem muito teoricamente, mas a gente só adquire a prática com 0 trabalho. Há uma necessidade de uma integração entre prática e teoria uma parceria entre as universidades e as escolas".

Na observação a estagiária acompanhou a melhora sensível dos alunos na prática de leitura. Verificou um uso intenso de filmes nas $5^{a}$ series. "Os sem floresta", seguido de um trabalho sobre o meio ambiente. "A guerra do Fogo", explica o que vão fazer e coloca uma questão: o que é homem no inicio do filme, e o que se torna? Nas $6^{a}$ séries inicia a aula contando uma pequena fabula: As três peneiras. Trata da necessidade ou não de se fazer fofoca. Isto porque todas as sextas séries estão tendo problemas de "mau comportamento". Apesar do livro 
didático ser marcante em suas aulas, pois é através dele que inicia as discussões da aula, tem a preocupação que os alunos compreendam o conteúdo. Não aceita qualquer resposta, induzindo-os a pensar, afirma a estagiária.

Trabalha uma historia sem sujeitos, e raramente localiza os fatos no tempo. Os períodos estudados ficam fragmentados e distantes dos alunos. Sua preocupação é com a compreensão das palavras, do texto em si mesmo. A estagiária registra também a postura de autoridade da professora, recebida com tranqüilidade e respeito pelos alunos. Quando a classe fica um pouco desatenta age de forma enérgica para "discipliná-los". Funciona, anota a estagiária. Ela é a autoridade dentro de sala de aula. Os alunos parecem entender isto, sem broncas.

As experiências pretéritas que parecem mobilizar seus conhecimentos é 0 ter sido alfabetizadora que a leva a enfrentar 0 analfabetismo das $5^{\mathrm{a}}$ séries e as dificuldades de leitura dos demais alunos preocupando-se com a compreensão de textos. A lembrança de seus pais narradores e "teatrólogos" do cotidiano parece mobilizar no presente o uso intenso de narrativas fílmicas e fábulas enfrentando a maledicência dos alunos das $6^{a}$ séries.

Paralelamente, sua participação e experiências com as questões sociais parecem mobilizar práticas de estudos do meio (visita à Sabesp, meio ambiente) que denotam uma preocupação da professora com a compreensão do espaço e nem sempre com os sujeitos que nele atuam evidenciado na analise da estagiária.

Estes saberes e práticas no presente parecem justificar o questionamento da professora com relaçã̃o a formaçã̃o docente atual, segundo ela mais teórica do que prática,defendendo a integração entre teoria e prática. Isto nos remete as colocações Tardif (1991) que conclui ser o saber da experiência o núcleo vital do saber docente. A prática redimensiona os saberes adquiridos

"antes e fora da prática profissional. Ela filtra e seleciona os outros saberes e por isso mesmo ela permite aos professores retomar seus saberes, julgá-los e avalia-los, e então objetivar um saber formado de todos os saberes retraduzidos e submetidos ao processo de validação constituído pela prática cotidiana."

Para o professor ex-seminarista, o objetivo da educação é tornar as pessoas felizes. A escola não é agradável ao aluno, não faz sentido para ele. "Uma educação que não gera felicidade, solidariedade e que não leve a motivação para a paz, para 
que serve?" Estes são eixos que devem articular o conteúdo significativo para o aluno, que devera estar relacionado à proposta da escola. "Essa felicidade é construída, ela envolve afetividade, conhecimento, relacionamento", completa o professor.

Acredita na educação para salvar o país. A grande dificuldade é motivar o aluno, trabalho do professor e do aluno também. "O segredo da motivação vem de dentro da gente, da alma. Gostar do que faz. E o aluno sente". Antes o professor era o detentor da verdade, hoje é um mediador. "A escola é um reflexo da sociedade. 0 mais agravante é que o aluno está saindo da escola sem condições de interferir nesta sociedade. A questão da agressividade, da violência, essa falta de ética que acontece lá fora, essa corrupção acaba acontecendo na escola".

Estas preocupações justificam a percepção da estagiária: a falta de uma proposta de curso em termos de temas e objetivos. Parece-me que a estagiária refere-se aos conteúdos conceituais, não contemplando os atitudinais, preocupação central do ex-seminarista, que valorizou o aprendizado da "boa comunicação com o público e a oratória".

Apesar de ser "viciado" no livro didático, o professor age sempre com motivação. Demonstra carinho pela classe e é recíproco. Nunca subestima os alunos nem corta sua fala. Tem bom relacionamento, sobretudo com os alunos da $5^{a} \mathrm{e}$ $6^{a}$ séries. Nestas séries ele "ousa" mais, observa a estagiária e propõe atividades diferentes, interativas. 0 mesmo não acontece com as $8^{\text {a }}$ que tendo muito mais meninas que meninos parece "inibi-lo" tornando as aulas monótonas.

As experiências pretéricas de comunicador e sacerdote são marcantes na mobilização dos saberes deste docente, ou seja, confere estatuto particular aos saberes da experiência. Estes parecem formatar os saberes curriculares advindos da oratória e comunicabilidade propiciados na formação do seminarista. Os saberes disciplinares são diluídos com e nas preocupações atitudinais identificadas pela estagiária.

Para o terceiro docente da geração mais velha, afirma que o professor que ensinou - lhe que "o governo vem do povo, e deve ser para o povo e pelo povo", deixou-lhe marca. Para este docente a educação pode reproduzir o sistema ou possibilitar sua transformação. Professor de Sociologia e Historia, propõe dois cursos no inicio do ano para os alunos votarem: Iniciação à Ciência Política ou Produção de Riquezas e Sexualidade.

No primeiro, discute as políticas institucionais, partidárias, procurando 
mostrar que todos somos seres políticos. Critica os meios de comunicação e os mecanismos presentes nas suas representações e mensagens. Procura levar o aluno a rever a sua posição de não gostar de política. 0 segundo curso foi a resposta encontrada para enfrentar o numero grande de alunas grávidas com onze anos. Sofreu muita perseguição e incompreensão quando começou. Hoje foi salvo pelos PCN que propõem os temas transversais.

Para este docente, a universalização da educação no Brasil, nos anos noventa do século passado desencadeou o processo de desmantelamento da escola. "No meu tempo somente 40\% da população estava na escola. Hoje quase 100\%. A escola não esta preparada para receber este pessoal". Há problemas de toda natureza, inclusive de infra-estrutura. Pensa-se a escola como a 30, 40 anos atrás. "Imagine um só banheiro feminino quando a maioria dos docentes é mulher. 0 intervalo não é suficiente para resolver o problema da fila".

A sua proposta é fazer com que os alunos entendam que fazem parte da construção histórica. "A aprendizagem tem um caráter helicoidal, de extratos diferenciados. Não é linear". Trabalha com a realidade social, no que é aceito pelos alunos e questionado pelas supervisoras.

Segundo o estagiário, o professor não utiliza livros didáticos, mas faz uma aula dialogada com temas variados. É extremamente didático e claro. Tudo que dizé muito bem argumentado. Passa o texto na lousa. "Provoca" os alunos com questões que às vezes desagrada. É um ótimo orador, discurso cativante e agressivo, fazendo piadas infames. Mas, não dá espaço para os alunos comentarem sobre os seus problemas e experiências. A fala firme e segura, aliada a fonte de dados que apresentou na lousa, sem indicação bibliográfica, parecem configurar segundo 0 estagiário um jogo retórico na qual a superioridade do professor é reiterada.

Entretanto, registra o dia da despedida do professor, pois agora será diretor. Os alunos não aceitavam o fato e foram mil abraços e agradecimentos, manifestações as mais variadas de apreço ao professor. Isto a meu ver pode parecer paradoxal tendo em vista seu egocentrismo e altivez enfatizado pelo estagiário. Seria talvez o componente do caráter científico ranço de sua formação técnica?

Ao ensinar o professor mobiliza vários conhecimentos numa perspectiva mais ampla dos problemas sociais Estes vestígios expressam o estudante de engenharia de produção, graduado em ciências sociais e geografia, (esta não concluída), mobilizando o seu saber docente. Por exemplo, observa o estagiário 
que o tema da sexualidade apesar de ser justificado pelo papel social da escola, nenhuma problemática histórica foi levantạda, restringindo-se ao caráter cientifico-biológico.

Seu processo de formação das exatas para as ciências sociais entrelaçam-se com sua memórias. Rejeitado nas academias militares por "hemo-afetividade", ex-coordenador da Pastoral da Juventude, ex-participante do movimento do custo de vida, este docente mobiliza seus saberes na direção de uma conscientização social, mantendo um traço autoritário, caminho encontrado na busca de sua individualização como também de seus alunos.

\section{Considerações Finais}

Um desafio metodológico enfrentado foi articular, no momento da análise, a discussão do saber escolar com a memória. Há muitas armadilhas, como por exemplo: infância pobre, porém com boas lembranças, idealização do passado em detrimento da pobreza que em certa medida ainda permanece nas suas condições de trabalho no presente; conquista/autonomia profissional do presente justificando o "abandono paterno" no passado. No exercício da analise é fundamental distinguir entre a fala, - a expectativa de corresponder ao que o entrevistador "deseja" ouvir - a lembrança e o esquecimento.

\footnotetext{
"Enquanto a memória lida com acontecimentos (...) o esquecimento desenvolve situações duradouras e que, nesse sentido podem ser chamadas de históricas, pois são constitutivas do trágico da ação. Assim, o esquecimento impede a ação de continuar, quer por confusões de papeis, impossíveis de desemaranhar, quer por conflitos insuperáveis que costumam remontar a épocas recuadas" (RICOEUR, 2007, p. 509).
}

Quanto à geração dos docentes podemos perceber que os nascidos na década de 40/50 há uma tensão implícita entre o espaço publico e o privado, um jogo entre o "esquecimento" da cidade/família e a lembrança dos movimentos sociais / greja Cátólica na construção de um sentido para sua experiência docente na sala de aula. Neste jogo cidade e família a ressignificação do espaço supera a ação dos sujeitos que nele agem. A tensão entre a busca de um espaço mais democrático e 
coletivo de ação, e na tentativa de ajudar o aluno apropriar-se deste espaço e no combate ao autoritarismo dentro de si, herança familiar, configuram professores "durões", autoritários, mas compreendidos e aceitos pelos alunos.

A geração da década de 60/70 a cidade é lembrada como espaço de conflitos, mas articuladora da compreensão do tempo presente. A tensão entre a lembrança do "público" - festas, casamentos, passeatas - e o "esquecimento" do privado, ocorre na busca da articulação dos dois espaços, pela ação conseqüente de seus sujeitos: professores e alunos. A leitura, recorrente nos depoimentos, vivenciada, sobretudo no espaço público, constitui o elemento articulador da historia pessoal e coletiva, auxiliando na identidade pessoal e profissional dos docentes. É evidente a mobilização dos saberes da formação acadêmica, sejam específicos como pedagógicos. A prática expressa uma postura flexível, a procura do que o identifica, a preocupação em fazer a diferença".

Para os dois profissionais, que embora vivendo os anos da abertura e movimentação política no país, não a mencionam em suas memórias, assim como para o mais jovem dos entrevistados, a família/escola são lembrados como espaços da autoridade (professoras mãezonas) e da humilhação. 0 eixo da mobilização das competências docentes parece ser o da esfera privada. Não são visíveis vestígios da sua formação acadêmica, aliás, figuras ausentes em suas lembranças.

() ato de relembrar é ambíguo, pois pensar a memória como uma espiral em (ex) tensão, que configura em seu movimento, planos diferenciados percorridos pelos sujeitos, significa entender esta tensão nos campos ou espaços da memória. Toda lembrança transforma-se à medida que se atualiza e ao fazê-lo, enriquece a percepção atual que, por sua vez, atrai outras lembranças.

Nossos depoentes expressam nos seus registros a valorização de suas memórias e o justificam explicitamente, pois afirmam que é muito bom compartilhar o "resgate do meu passado, da minha historia "; "Recordar é dar um significado maior a essa vivência, entender um pouquinho daquilo que passou"; "oportunidade de falar pra vocês, coisas concretas da minha experiência profissional, coisas que só eu sei. Falei de outras coisas, de uma maneira onde foi possível, até pela sequiência que vocês propuseram amarrar algumas coisas,";" Isto fica até como uma troca de experiências, não é?"; "Eu me senti a vontade. Estava preocupado com essa relação. Mas eu gostei de ter vivido esta experiência, de ter contado. Principalmente porque eu peço para que os meus alunos façam isso. Então foi um momento em que eu vivi 
o outro lado. Acaba sendo uma coisa interessante e me ajuda -como eu falei a gente nunca deixa de ser professor- a entender um pouco melhor os alunos".

Contudo fica evidente a tensão, pois declaram ser "um pouco assustador, no inicio", "Bem estranho", "meio constrangedor", "meio complicado isso aí. Por que você conta a historia, mas você não conta a historia, você pincela algumas coisas de sua vida".

Apesar da tensão, justificam porque consentiram em registrar suas memórias. "Daqui a cem anos um pesquisador vai ver como pensava o professor da rede. Como ele vivia como é que era esse cotidiano. Mais para frente isso pode resolver algumas perguntas do futuro".

O registro das entrevistas e das observações das aulas expressaram dimensões de contradições, conflitos e ambigüidades vivenciados no processo de vida pessoal e de formação profissional, reforçando práticas "tradicionais", mas também expressaram tentativas de interagir com o tempo presente, reformulando práticas e valores e resistindo a outros.

E.P.Thompson, (1988) no seu estudo sobre a mudança nos significados e vigor de costumes e tradições populares no processo de constituição dos sujeitos sociais, reconhecendo a impossibilidade de uma pura volta ao passado, lembranos que há maneiras de se fazer indagações sobre esse passado e de aproveitar algumas indicações para o futuro. Na explicitação da fala dos professores, sobre suas experiências presentes e passadas e nas perspectivas futuras, identificamos questões novas, emergentes nesse processo.

\section{Referências}

CHERVILL, André. História das disciplinas escolares: reflexões sobre um campo de pesquisa. Teoria \& Educação, n.2, 1990, p.177- 229.

CIAMPI, Helenice. O desafio da historia local. In: MONTEIRO, Ana Maria; GASPARELLO, Arlete e MAGALHÃES, Marcelo de Souza (org.) Ensino de Historia: sujeitos, saberes e práticas. Rio de Janeiro: Mauad X: FAPERJ, 2007, p.199-214.

MEIHY, José Carlos Sebe Bom. Manual de História Oral. 5.ed. São Paulo: Loyola, 2005.

PERRENOUD, P. Construir competências desde a escola. Porto Alegre: Artes Médicas, 1999. 
RICOEUR, Paul. A memória, a bistória, o esquecimento. Campinas, S.P.:Editora da UNICAMP, 2007.

SAMUEL, Raphael. Teatros de Memória. Projeto História. São Paulo, n.14, 1997, p.41-81.

SEIXAS, Jacy Alves de. Os tempos da memória: (des) continuidade e projeção. Uma reflexão (in) atual para a História? Projeto História, São Paulo, n.24, 2002, pp.43-63.

TARDIF, LESSARD e LAHAYE. Os professores face ao saber. Esboço de uma problemática do saber docente. Teoria e Educação. Porto Alegre: Pannonica Editora, n.4, 1991.

TARIIIF, Maurice. Saberes Docentes e Formação Profissional. Petrópolis: Vozes, 2002.

THOMPSON, E.P. "Introdução: costume e cultura". Costumes em comum, estudos sobre cultura popular tradicional. São Paulo: Companhia das Letras, 1998, p.13-24.

THOMPSON, Paul. História oral e contemporaneidade. História Oral, S. P., n.5, 2002, p.9-28.

WARDE, Mirian Jorge e CARVALHO, Marta Maria Chagas. Política e Cultura na produção da História da Educação no Brasil. Contemporaneidade e Educação. Revista de Ciências Sociais e Educação. Rio de Janeiro, Ano V, n. 7, 2000, p.9-33.

\section{Memorios and practices in Mistory teaching and survey}

ABSTRACT

The test aims to socialize the results and problems we have faced in the project School Knowledge:memóries and practices of the History teachers in the municipal net of S.Paulo which has been coordenate by me since 2005 at PUCSP. I will explain the problemátic, aims and methodology having as focusthe research of 2007,in the submayorhall of Vila Nova Cachoeirinha and Casa Verde.

Key-words: history teaching- school knowledge - teaching knowledge. 